\title{
Cyclists in shared bus lanes: could there be unrecognised impacts on bus journey times?
}

Rachel Aldred BA, MSc, PhD, FHEA, MCIHT

Reader, Department of Planning and Transport, Faculty of Architecture and the Built Environment, University of Westminster, London, UK

(corresponding author: r.aldred@westminster.ac.uk)

Luke Best

Managing Director, Multimodal, Birmingham, UK

Phil Jones BSC, MICE, MCIHT, FIHIE

Managing Director, Phil Jones Associates, Birmingham, UK

This paper contributes to debates around improving the modelling of cycles, through an exploratory case study of bus-cycle interactions in London. This case study examines undocumented delays to buses caused by high volumes of cyclists in bus lanes. It has generally been assumed that cyclists do not noticeably delay buses in shared lanes. However, in many contexts where cyclists routinely share bus lanes, cyclist numbers have historically been low. In some such places, bus lanes are now seeing very high volumes of cyclists, far above those previously studied. This may have implications for bus - and cycle - journey times, but traditionally traffic modelling has not represented the effects of such interactions well. With some manipulation of parameters taken from models of other cities, the model described here demonstrates that cycles can cause significant delays to buses in shared lanes, at high cycling volumes. These delays are likely to become substantially larger if London's cycling demographic becomes more diverse, because cyclist speeds will decline. Hence bus journey time benefits may derive from separating cycles from buses, where cycle flows are high. The project also suggests that microsimulation modelling software, as typically used, remains problematic for representing cyclists.

\section{Introduction}

Microsimulation modelling has substantially improved the ability to understand interactions in different traffic conditions. The approach represents vehicles individually, using distributions to model heterogeneous behaviour, such as differing levels of gap acceptance by drivers. These parameters can be adjusted to be specific to cities, countries or regions.

With increasing computing power, microsimulation can represent ever more complex traffic systems (Kara et al., 2014; Wood, 2012). These new possibilities bring new challenges. Microsimulation, like other transport modelling methods, has been shaped by traditions of car dominance and car dependency (Naess et al., 2014). As Kretz et al. (2013: p. 2) comment

[E]laborate methods for the planning of vehicular traffic in cities have been developed and are in perpetual use. With these tools often the vast majority of awareness and working hours are invested in vehicular traffic with the implicit assumption that cyclists and especially pedestrians always 'somehow' will make their way.

This has encouraged the development of specific pedestrian modules and dedicated pedestrian simulation models (Kretz et al., 2013). Microsimulation modelling of cyclists is by contrast based on driver behaviour and vehicle characteristics, using different parameter distributions (e.g. speed). However, using default parameters, modelled cyclist behaviour may appear odd or unlikely: waiting behind cars in the middle of a congested lane, or failing to 'bunch up' with high numbers of cyclists. Kohli et al. (2014) comment that there is a reduction in effective passenger car units (PCUs) per cyclist at times when there are higher cycling volumes. This is likely due to such behaviour, often not captured in traditional traffic models.

Some problems may be addressed by parameter adjustment, although often default parameters are used in modelling, if cyclists are included at all. A more fundamental issue remains: are cyclists basically similar to cars, or - like pedestrians different in kind? The project described here explores these issues in modelling cyclist-bus interactions in one London location (London Bridge northbound carriageway), using PTV Vissim.

In countries with higher levels of cycling, such as Denmark and the Netherlands, bus lanes are not generally seen as cycle infrastructure, although cyclists may at times share space with buses, for example in city centres with restricted car access. By contrast bus lanes in the UK, which are mostly shared with cyclists as well as taxis and sometimes also motorcycles, have long been considered a core part of cycle and bus provision (Cycling England, 2010; although see also TfL, 2015b). Many argue (e.g. TRL, 2004) that shared bus lanes are win-win: cyclists benefit from reduced mixing with motor traffic, without delaying buses. The present paper explores the extent to which the second assumption is true when cycle flows are high. It has policy relevance for cities seeking to grow cycling, particularly among currently under-represented demographics, while supporting other sustainable modes (GLA, 2013). 
Research focusing on cyclists in shared bus lanes is surprisingly rare. A study by TRL (2004) surveyed cyclists (largely men aged 25-39) using bus lanes at six sites in Edinburgh, Hull, Derby and London. It found bus lanes 'very popular' by comparison to typical local traffic conditions. To some extent, this is unsurprising. The survey targeted those choosing to use bus lanes; moreover 'typical traffic conditions' were likely to be poor. However, the study does suggest that, for current cyclists, in the UK often young-to-middle-aged men, bus lanes are seen as superior to mixing with general traffic. Wider restrictions on cyclists using bus lanes would cause a deterioration in cycling environments and probably also a reduction in cycling.

More recent research, however, suggests bus lanes are unlikely to encourage mass cycling among a wider demographic. Stated preference studies involving cyclists and non-cyclists (TfL, 2010, 2012) showed bus lanes are not viewed as preferable to painted advisory cycle lanes, although both are seen as better than nothing (see Figure 1). Both bus lanes and painted cycle lanes are seen as unsuitable for cycling with or by children (Aldred, 2015). Separated cycle infrastructure is substantially preferred by both existing and potential cyclists, particularly currently under-represented groups (Kohli et al., 2014; TfL, 2010, 2012). Figure 1 illustrates the change in a nominal measure of 'utility' related to different types of infrastructure improvement, based on a Transport for London (TfL) study (TfL, 2010).

In London, the development of separated cycle infrastructure has been criticised as likely to cause bus delays, for example by
London TravelWatch, an organisation that represents the capital's transport users (London TravelWatch, 2014). Underlying this claim is an assumption that the status quo has no impact on bus journey times, and therefore any reallocation of space and time towards cyclists can only be negative (or at best neutral) for bus journey times. This belief is expressed in much UK policy literature. Cycling England (2010: p. 2) design guidance on bus lanes and bus stops states

The primary factor affecting delay [to buses] is the width of the bus lane (A minimum of $4 \mathrm{~m}$ is suggested in the guidance to

allow buses to pass cycles within the lane. However, given a $1 \mathrm{~m}$ dynamic envelope for a cycle, and a $2.5 \mathrm{~m}$ bus width, this would imply potentially a very close pass $(0.5 \mathrm{~m})$. Current TfL draft guidance on accessible bus stops cites $4.5 \mathrm{~m}$ ). However, even with $3 \mathrm{~m}$ wide lanes, most cases of delay involve buses slowing down behind a cyclist before stopping at a bus stop. This is unlikely to have much effect on overall bus punctuality. Most cyclists try to avoid delaying buses, either by cycling faster or by allowing buses to pass.

This seems to be based on the TRL (2004) paper, where observers recorded impressions of whether buses and cycles delayed each other: their busiest route for cycling carried a maximum of 100 cyclists per peak hour. It would be difficult to use this method for much higher flows, yet an increasing number of UK towns and cities now experience far more than 100 cyclists per peak hour within shared bus lanes. Although authors now suggest that higher volumes may significantly delay buses and other traffic (Wedderburn, 2015: p. 12), little work has been done to quantify this (Kohli et al., 2014).

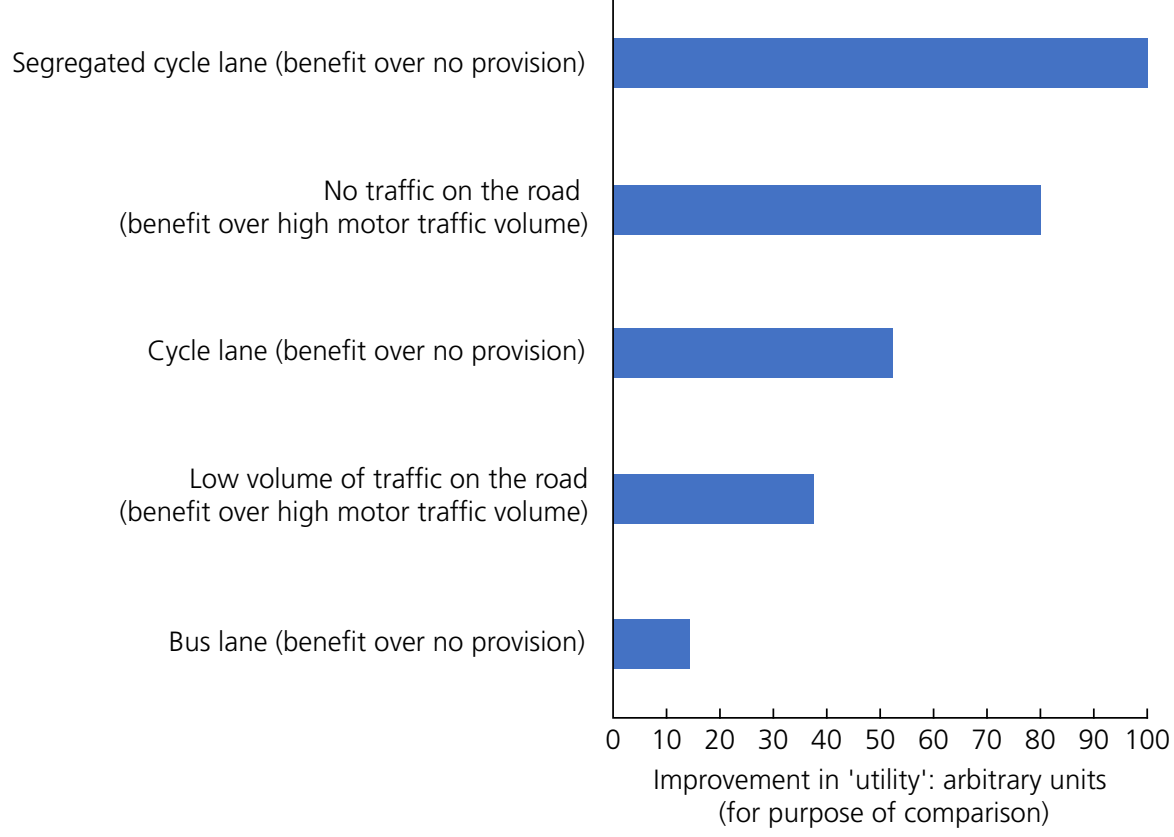

Figure 1. Stated preferences for different types of cycle infrastructure among Londoners (source: adapted from TfL (2010)) 
If shared bus lanes at high cycling flows might substantially delay buses, separating the two would bring intrinsic bus journey time benefits that could - in theory - negate disbenefits due to changes in junction timing and/or reduction in dedicated bus space. The impact on buses of creating segregated space for cycles on or in parallel with bus routes would thus become something to be judged on a case-by-case basis. That would involve measuring current (and future) delays to buses caused by sharing with cycles, and examining whether these would be outweighed by any losses caused by reduction in space or time priority for buses. The case study presented here sketches out a simplified version of this approach.

\section{Context}

\subsection{Context: London}

The study used PTV Vissim (Version 8.00-05 (57518)) to produce a microsimulation model exploring the impact of cycles on bus journey times at one location in London. Vissim was used because of its successful application in COWI (2013) to model cyclist flows; meaning that the team had access to these non-standard parameters as a starting point.

Owing to interest in the impact of high cycling flows, and to keep the model simple (covering only a link section), the northbound carriageway of London Bridge was selected. The impact of cycles on buses at junctions may be different (see Kohli et al., 2014); and relationships characterising London Bridge may not apply elsewhere. Therefore, the research is exploratory. It does, however, represent a first attempt to test the possible presence and establish the potential magnitude of delays to buses caused by high cycling flows in a London context. The approach is likely to be increasingly relevant in congested cities as cycling grows.

London has an excellent public transport system, with major recent investment in bus priority measures. It experiences congestion, particularly at peak times in inner and central areas, alongside ongoing population growth. A Department for Transport (DfT, 2004) report on London's early bus priority measures concluded that bus journey times had not substantially improved, but that without these measures, journey times would have lengthened further. Despite relatively limited impact on delays, bus priority measures did change perceptions of London's buses, improving reliability and achieving mode shift (TfL, 2009). London's mode shift towards sustainable modes continues (TfL, 2015a, 2015b). However, there are tensions between buses and cycling, with demands for segregated cycling infrastructure seen as causing problems for buses.

London has seen strong growth in cycling in recent years from a low base: cycling now carries as many people as do the city's Docklands Light Railway and taxis combined. In recent years, there has been a substantial uplift in investment (GLA, 2013), although lagging well behind investment in public transport modes. The cycling mode share is currently $2 \%$ for London overall, but on busy corridors - often Transport for London Road Network routes, which also form part of the city's Bus Priority Network - flows of 800 cycles per peak hour and more are now routinely recorded on key routes (TfL, 2013a). Figure 2 shows the London Bridge area in Central London context.

\subsection{London Bridge case study}

London Bridge is one of six bridges that both cyclists and motorists can use to cross the Thames between Westminster and the Tower of London. Morning peak hour flows on the northbound carriageway are around 2000 vehicles/h, over half being cycles. This northbound carriageway has one bus lane and two general motor traffic lanes, all of which are relatively narrow (c. $3 \mathrm{~m})$.

Considering people flows, Table 1 shows that cyclists using the bridge easily exceed people travelling by car, taxi, light and heavy goods vehicle (HGV), and motorcycle combined. Figures provided by TfL for bus occupancy on this corridor during the morning (a.m.) peak are 27 passengers per bus. Normally, however, bus numbers would be approximately 100 based on scheduled services: this was lower (58 buses) during the data collection period due to roadworks in the area.

Hence Table 1 provides two estimates of bus occupancy; the first uses 27 passengers per bus and the second 47 passengers per bus (assuming a proportionally raised occupancy due to fewer buses serving the routes during the surveyed period). In the first case, a third of person-flow is made up of cycles and $42 \%$ bus passengers; in the second, a quarter of person-flow consists of cycle users and over half consists of bus passengers. The car/van/taxi occupancy figure of 1.2 has been taken from average English car or van occupancy rates for commuting and business trips, likely to dominate flows during peak hour (DfT, 2016). Motorcycle and HGV occupancy figures given by Banister (2008) were used.

\section{Methods}

\subsection{Microsimulation of cyclists}

Although microsimulation provides the ability to model road user behaviour accurately, most studies have not done this for cyclists (Twaddle et al., 2014). As COWI (2013: p. 7) comments

During simulations of road traffic, cyclists and pedestrians are usually included to represent their effect on road capacity. [...] Whether the cyclists' behaviour is correctly represented is normally not considered, as they are not the primary focus.

But where cyclist volumes are high, modelling their behaviour unrealistically could lead to incorrect assumptions about capacity. Kohli et al. (2014) argue that PCU values for cyclists - a 


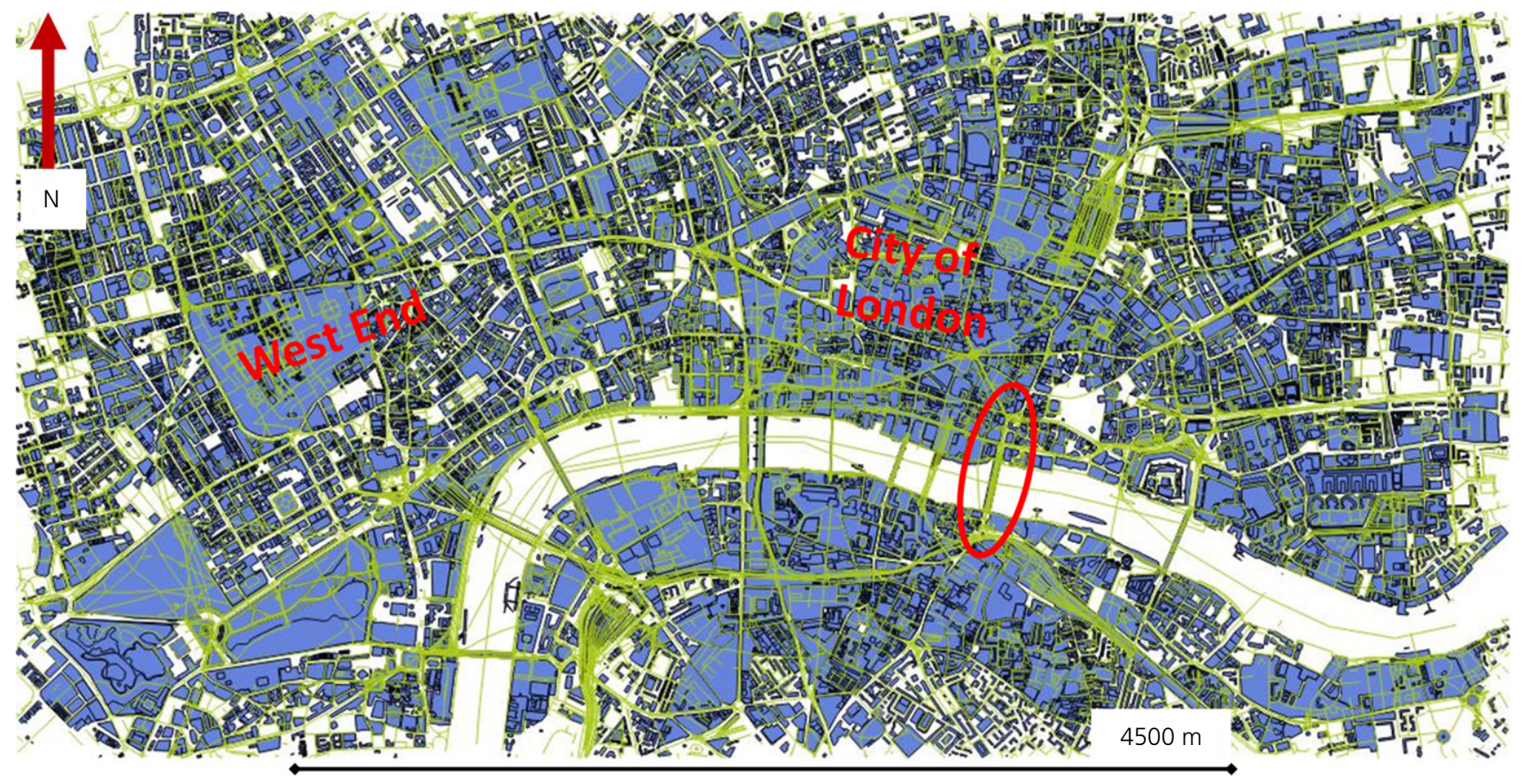

Figure 2. London Bridge area. A full-colour version of this figure can be found on the ICE Virtual Library (www.icevirtuallibrary.com)

Table 1. Vehicular and person flow on London Bridge northbound a.m. peak (8-9 a.m.)

\begin{tabular}{|c|c|c|c|c|c|c|}
\hline & Pedal cycle & Motorcycle & Bus & Light vehicle & Heavy vehicle & Total \\
\hline Hourly vehicle total & 1201 & 287 & 58 & 460 & 41 & 2047 \\
\hline Vehicles: $\%$ of total & 59 & 14 & 3 & 23 & 2 & 100 \\
\hline Occupancy: persons/vehicle & 1 & $1 \cdot 1$ & $27 / 47$ & $1 \cdot 2$ & $2 \cdot 3$ & - \\
\hline People \#1 (low bus estimate) & 1201 & 316 & 1566 & 552 & 94 & 3729 \\
\hline People \#2 (high bus estimate) & 1201 & 316 & 2726 & 552 & 94 & 4889 \\
\hline People \#2: \% of total & 25 & 6 & 56 & 11 & 2 & 100 \\
\hline
\end{tabular}

key measure of capacity in traditional models such as Saturn and Transyt - vary depending on the road infrastructure. Where cycling flows are low, this may not matter; however, at high volumes, modelled capacity may be highly sensitive to assumptions about cyclist behaviour.

Vissim, like many microsimulation tools (e.g. Aimsum, Sumo), uses discrete time intervals and independently models longitudinal and lateral motion. The longitudinal approach is space continuous, utilising a 'car following model'. Lateral movement of motor vehicles is modelled using a discrete lane choice model, where position and speed of other road users and the desired route of the individual vehicle are taken into account in the lane-choosing process (Twaddle et al., 2014: p. 141). For cyclists, such behaviour seems unrealistic, with platooning and under- and overtaking within a lane likely. But incorporating this natural feature of cyclist behaviour requires adjusting parameters because it is not 'natural' vehicle behaviour in existing models. Hence to include something resembling the typical behaviour of cyclists, it is not sufficient to use the parameters given in currently available modelling software. COWI (2013) used a continuous lateral access to model cyclist behaviour in Vissim, also used here, which provides a more realistic depiction of cyclist behaviour.

Different aspects of cyclist behaviour may present different levels of problem. Twaddle et al. (2014: p. 145) divide (potentially) modelled cyclist behaviour into three categories: operational, tactical and strategic. The strategic level is outside this project's remit, referring to 'planning the trip and selecting a route'. 'Operational' behaviour means 'automatic actions carried out by a bicyclist to control the bicycle and ride through the traffic environment'. 'Tactical' behaviour by contrast 'includes short term maneuvers that a bicyclist consciously selects to deal with the current traffic situation', such as swerving and deceleration to avoid collisions. Twaddle et al. (2014) conclude that, with calibration using field data, operational cycling behaviour (but not, perhaps, tactical behaviour) can be accurately modelled using software such as Vissim, although often this is not done. 
Table 2. Key model parameters

\begin{tabular}{|c|c|c|}
\hline Adjusted parameter & Initial parameters & Process of adjustment \\
\hline $\begin{array}{l}\text { Cyclist behaviour - speed } \\
\text { distributions }\end{array}$ & $\begin{array}{l}\text { COWI cyclist speed } \\
\text { distributions }\end{array}$ & $\begin{array}{l}\text { As described below, the distribution was iteratively shifted until the modelled bus } \\
\text { journey times corresponded to those measured }\end{array}$ \\
\hline $\begin{array}{l}\text { Cyclist behaviour - acceleration } \\
\text { and deceleration }\end{array}$ & $\begin{array}{l}\text { COWI cyclist speed } \\
\text { distributions }\end{array}$ & No change \\
\hline $\begin{array}{l}\text { Cyclist behaviour - following } \\
\text { parameters }\end{array}$ & COWI cyclist behaviour & $\begin{array}{l}\text { Due to the high volume and higher speed, the minimum look-ahead distance was } \\
\text { increased from } 20 \mathrm{~m} \text { to } 40 \mathrm{~m}\end{array}$ \\
\hline $\begin{array}{l}\text { Cyclist behaviour - overtaking } \\
\text { parameters }\end{array}$ & COWI cyclist behaviour & $\begin{array}{l}\text { Minimum headway (front/rear) was decreased due to observed cyclist behaviour at } \\
\text { this site }(0.5 \mathrm{~m} \text { to } 0.2 \mathrm{~m}) \text { and 'consider subsequent static routing decisions' was } \\
\text { ticked }\end{array}$ \\
\hline $\begin{array}{l}\text { Bus driver behaviour - } \\
\text { overtaking parameters }\end{array}$ & TfL Vissim template & Advanced merging behaviour turned on, as advised for new models \\
\hline
\end{tabular}

The process began by using parameters for traffic behaviour provided by TfL, which adjust default Vissim parameters to reflect London driver behaviour. Following this, the project's main starting point for model parameters was a recent study in Copenhagen, Denmark (COWI, 2013). The COWI study sought to represent the capacity and behaviour related to cyclists as accurately as possible. It involved large-scale data collection and analysis, followed by a lengthy technical process to create a far more accurate Vissim cyclist template. This provided an excellent starting point for the model. However, during calibration the COWI parameters had to be adjusted to represent London cyclist (and bus driver) behaviour.

The COWI study identified ten key parameters for the microsimulation of cyclists.

Basic parameters are

vehicle characteristics

- speed distributions

- acceleration (and deceleration) distribution.

Parameters regarding bicycle paths are

- following parameters

- overtaking parameters

- behaviour at narrowing sections

- behaviour at bus stops.

Parameters regarding intersections are

- behaviour in waiting zones

behaviour at stop lines

- behaviour at right turns.

For this study the five emphasised in italics are key. There were insufficient site data to look at different vehicle characteristics (i.e. types of cycles); in any case cyclists tended to be using standard cycles (i.e. not e.g. cargo cycles). The site did not have narrowing sections, waiting zones, stop lines, or right turns.
Table 3. Vissim bus journey time data: comparative effect on bus journey times

\begin{tabular}{|lcc|}
\hline Scenario & Median journey time: s & Increase: \% \\
\hline No cyclists & $22 \cdot 4$ & - \\
London cyclists & $26 \cdot 5$ & 18 \\
Copenhagen cyclists & $32 \cdot 6$ & 46 \\
\hline
\end{tabular}

All cycle settings were initially set to match COWI settings. An iterative process involved slowly adjusting settings to achieve validation against site-specific data. Another key element has been the behaviour of buses, and to a lesser degree general traffic, important to achieve a realistic understanding of the impact of cyclists on other vehicles.

\subsection{Parameter adjustment summary}

Tables 2 and 3 summarise parameter adjustment, also highlighting differences between Vissim default settings, TfL 'London' settings, COWI cyclist settings, and the final settings used. Default and TfL do not refer to cyclists specifically, but to all vehicles on urban links. The COWI and multimodal/London Bridge settings are applied specifically and only to cyclists on those urban links, with general traffic/vehicles being controlled by the settings in the TfL behaviours.

The adjustment process is described in detail below in relation to cyclist speed, where the parameters used required substantial change. Further details of parameters used are in the Appendix, including more detail about the other four key parameters and how these were manipulated to provide greater realism than offered by the default parameters. For example, buses were allowed free lateral positioning so that they can overtake cyclists.

\subsection{Network coding}

The network was coded using the inbuilt mapping services within Vissim to create an accurately scaled background. As the focus was interaction between buses and cyclists in a bus lane, only the northbound movement across London Bridge 


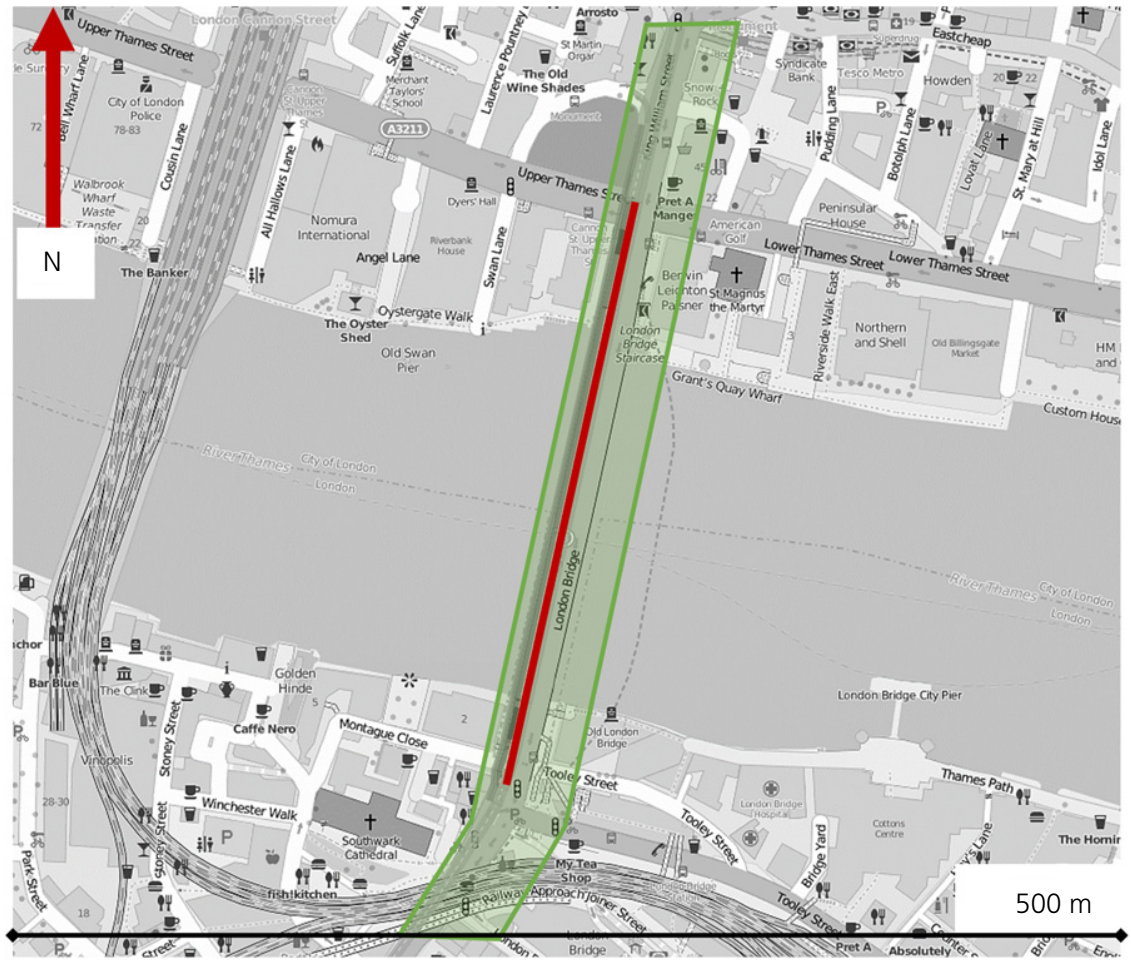

Figure 3. Study site (@ OpenStreetMap contributors)

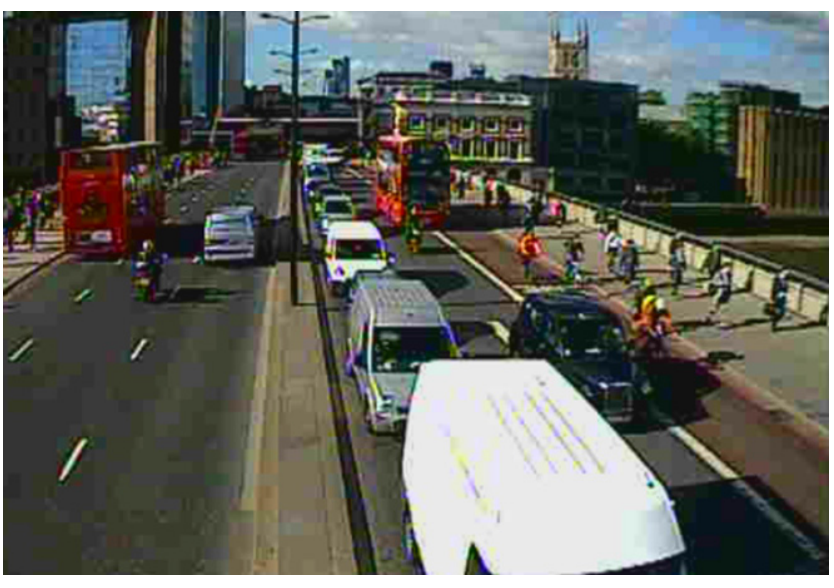

Figure 4. Example video capture image (camera facing south)

was modelled. This included the bus lane (nearside lane) and two general traffic lanes (middle and outside lanes). Figure 3 shows the extent of the study site.

\subsection{Traffic counts and data collection}

A comprehensive data collection exercise was carried out by PCC Traffic Information Consultancy during May 2015. This involved a series of video surveys, positioned at key intervals along London Bridge to capture northbound movement, which allowed the provision of detailed manual classified counts of vehicle totals in each lane, also capturing vehicle volumes for any traffic straddling lanes - that is while overtaking cyclists. Figure 4 shows an example video capture image during peak hour.

Travel time data were collected for all buses, between southern and northern bus stops. All data were collected over a $5 \mathrm{~d}$ period, to cover morning, midday and evening peaks. The a.m. peak (8.00-9.00) had significantly higher northbound traffic flow compared to the midday and p.m. peaks, particularly in terms of the number of cyclists (1201 compared to 95 and 347, respectively). Therefore, the morning was chosen as the most appropriate peak hour to model. Buses were entered at exact times throughout and cycles entered in 5 min volumes, based on the detailed surveys.

\subsection{Vissim model specification}

The specification for the Vissim model is itemised below.

Vissim version: 8.00-05.

- Testing year: 2015 .

- Time period: a.m. peak period, 7.45-9.00 (including 15 min warm-up period).

Evaluation period: a.m. peak, 8.00-9.00.

Vehicle types defined: cars, HGVs, buses, motorcycles, pedestrians and cyclists. 
Results evaluation method: models have each been run over five random seed profiles to reflect day-to-day variations in traffic patterns and profiles; the results have then either been averaged or used in full.

\subsection{Speed distributions}

After the initial calibration exercise, ensuring the correct traffic volumes were present, the model was validated using observed bus journey time data. Bus routing was modelled assuming buses stopped at one stop, but not both (as per video observations). During this process, data from five random seed runs was used each time to give a representative comparison to the $5 \mathrm{~d}$ worth of site data. The validation was assessed using standard criteria in the UK Design Manual for Roads and Bridges. These state that modelled journey times compared with observed journey times should be within $15 \%$ (or a minute, if higher) for $85 \%$ of the routes (DfT, 1996: p. 71).

The COWI profiles for cyclists' desired speeds proved inappropriate. When used, modelled bus journey times were substantially longer than the observed times, implying London Bridge cyclists are riding (or trying to ride) much faster than Copenhagen cyclists, even using downhill Copenhagen settings. An initial adjustment of the speed profiles was further refined, based on site observations of cyclists travelling across the segment in question, to give the final profile. Only $7 \%$ of London Bridge cyclists have a desired speed of under 19 miles $/ \mathrm{h}$ $(30 \mathrm{~km} / \mathrm{h})$, while this is true of almost all Copenhagen cyclists, even on downhill sections.

The speed distribution presented here represents a segment where both desired and actual speeds are likely to be relatively fast, compared to journey averages. People are cycling to or from work on a segment with no intersections, bends, crossings, parking or loading, and where the speed limit for motor traffic (with which they mix) is 30 miles $/ \mathrm{h}(48 \mathrm{~km} / \mathrm{h})$. The platooning here means cyclists are effectively 'drafting' each other, reducing wind resistance. Indeed, London Strava data records riders obtaining achieved speeds of $20-25 \mathrm{miles} / \mathrm{h}(32-40 \mathrm{~km} / \mathrm{h})$ and even $25-30 \mathrm{miles} / \mathrm{h}(40-48 \mathrm{~km} / \mathrm{h})$ despite this covering a longer London Bridge segment, including a junction likely to slow cyclists down (Strava, 2017a, 2017b). The academic literature on achieved cycling speed tends: $(a)$ to focus on whole-journey speeds (e.g. El-Geneidy et al., 2007), which will be much lower than peak segment speeds, or $(b)$ to focus on speeds through intersections (e.g. Pein, 1997), which will be relatively low, or areas where there is much more interaction with pedestrians and/or vehicles pulling in and out (e.g. Davies et al., 2003; Singh, 2012).

The high desired and actual cyclist speeds (Figures 5 and 6) calculated across this section do not imply whole-journey speeds are much faster in London than Copenhagen. That will depend on factors such as traffic light phasing; and

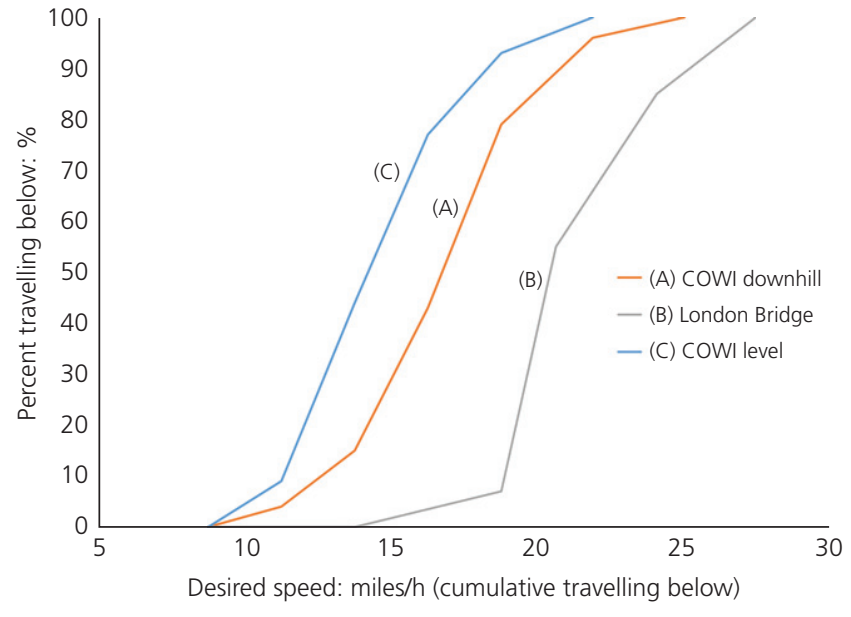

Figure 5. Comparison of three cyclist speed profiles (Vissim desired speed parameters)

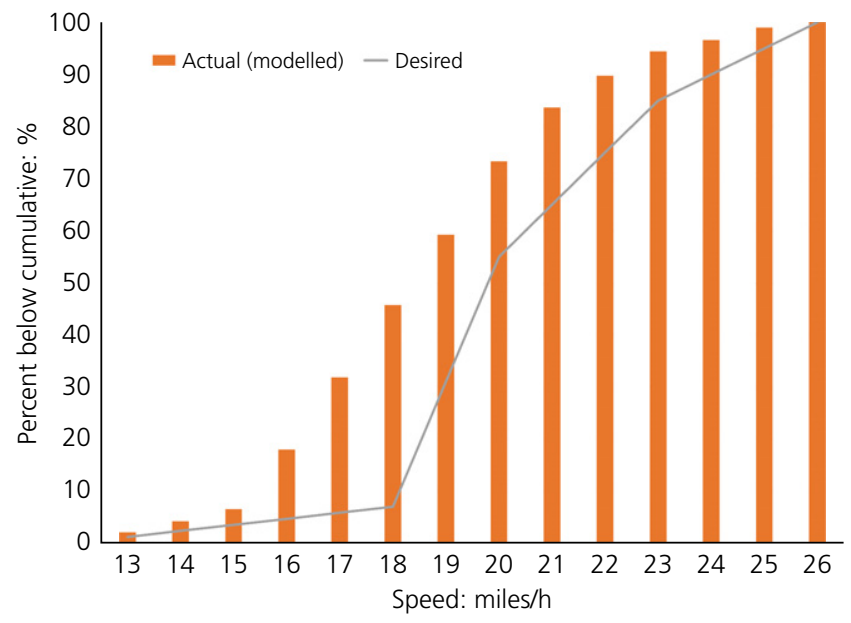

Figure 6. Achieved compared with desired speeds at baseline, modelled cyclists on London Bridge

Copenhagen has introduced 'green waves' for cyclists to reduce the time they spend stopped at red lights. However, maintaining or even attaining a speed of $20 \mathrm{miles} / \mathrm{h}$ is likely to be challenging for many potential riders, especially women, whose speeds tend to be lower than men's (Aldred and Crosweller, 2015).

It should be noted that many cyclists did not attain their desired speed over the bridge. Specifically, 55\% of cyclists had a desired speed of $20 \mathrm{miles} / \mathrm{h}$ or less, while $73 \%$ travelled through this section at $20 \mathrm{miles} / \mathrm{h}$ or less. Given the conditions here (relatively conducive to high speeds - no side roads, car parking, or junctions) this may indicate the potential of buses to delay cycles, although this is not the focus here. 
Cyclists in shared bus lanes: could there be unrecognised impacts on bus journey times?

Aldred, Best and Jones
Figures 7 and 8 demonstrate the difference when using the bespoke and COWI profiles. Using the COWI level desired speed profile, only $51 \%$ of bus journeys validated correctly. Using the
'London Bridge' profile, $85 \%$ of bus journey times fall within the surveyed range. Figures 7 and 8 illustrate the two profiles in comparison to recorded bus journey times between 8 and 9 a.m.

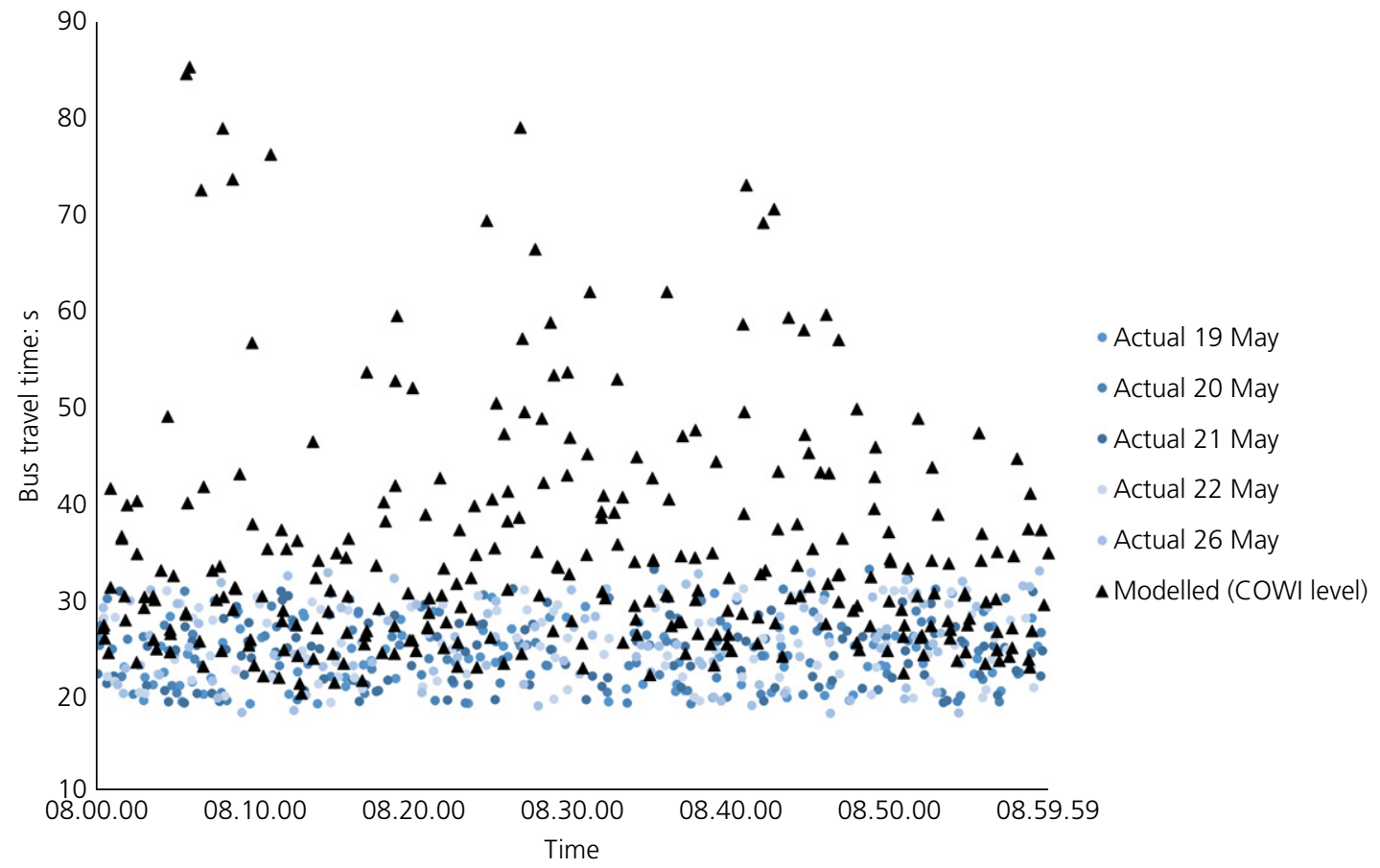

Figure 7. Vissim bus journey time data: COWI level path setting

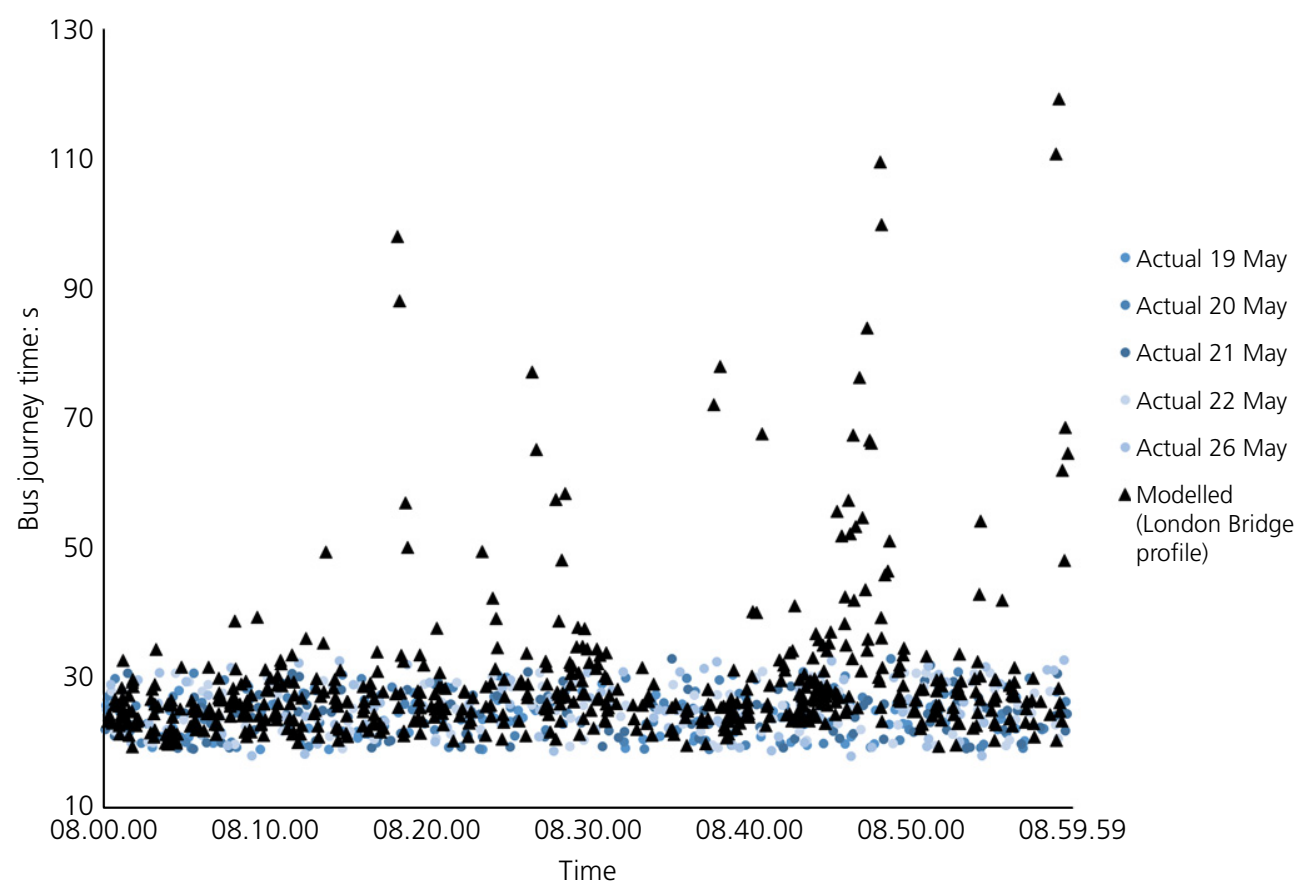

Figure 8. Vissim bus journey time data: London Bridge profile 
It should be noted that the model is relatively simple and is unable, for example, to include the split cycle and offset optimization technique split cycle and offset optimization technique (Scoot) settings used across the London network, which aims to improve network resilience to delays by re-timing signals when needed. This may contribute to the appearance of occasional very high bus journey times within the model, particularly towards the end of the peak hour, whether modelling baseline or alternative scenarios. Hence median rather than mean journey times are used here to illustrate delay. The use of means would skew the modelled delays upwards because of these occasional anomalous results; whereas the modelled and actual baselines were much closer in terms of medians.

Figures 9 and 10 illustrate how much closer the medians are than the means, for modelled and actual baseline data. However, the medians remain systematically high, albeit to a much lesser extent. This reflects the exploratory nature of the

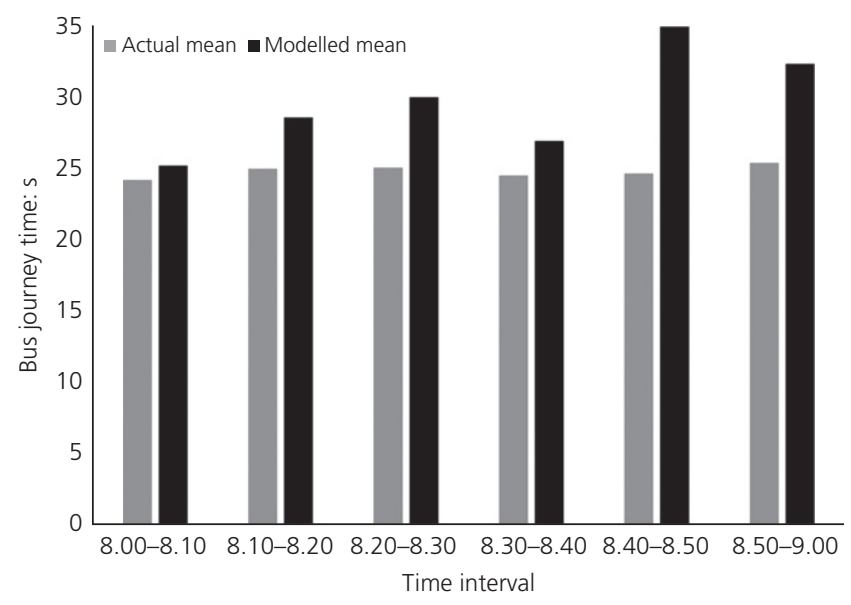

Figure 9. Actual and modelled baseline data: comparison of means, 10 min intervals

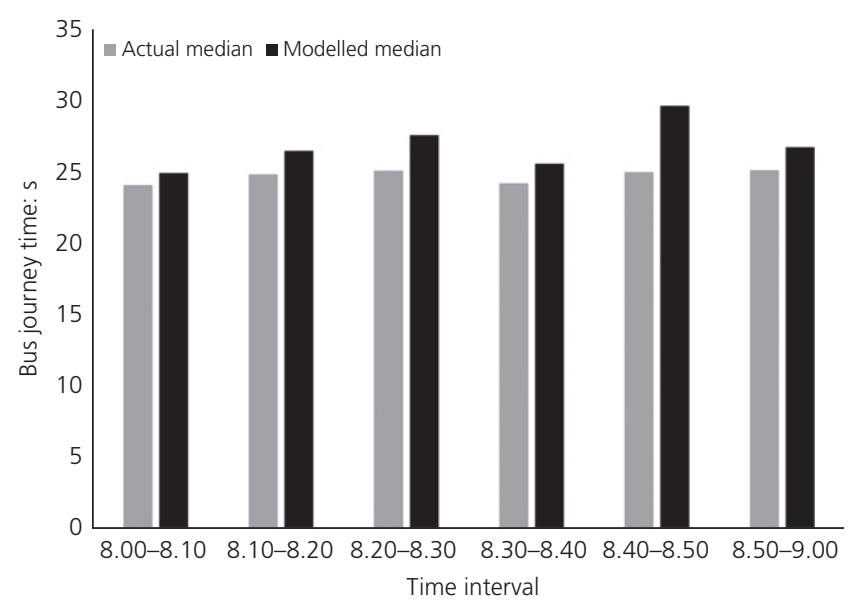

Figure 10. Actual and modelled baseline data: comparison of medians, 10 min intervals model and the limited research backing for the parameters and underlying assumptions. A measurable delay exists, but this small-scale piece of work was unable to capture it entirely accurately. The paper returns to this point in discussing the need for further research and data collection in this area to support better modelling.

\section{Findings}

Once the calibrated model achieved a suitable fit between modelled and observed bus journey time data, results were compiled to measure any delays buses experienced travelling northbound along the stretch of bus lane on London Bridge. Delay was measured as the increase in journey time comparative to a sample scenario run with no cyclists. Journey times were measured between bus stops on either side of the bridge, sufficiently away from the bus cages that buses stopping to board/alight passengers were not included in any delay calculation. General traffic had only a minimal effect on bus delays in the 'no cyclists' scenario, being mostly limited to the outside lane, even during the busiest morning peak.

Table 3 shows median bus journey times for each scenario at peak hour, along with the percentage increase over the 'no cyclist' model (representing the amount of delay caused by the flow of cyclists). Current volumes of London cyclists are associated with a median $18 \%$ increase in peak hour bus journey times, while the same volumes of Copenhagen cyclists (riding as per the COWI level profile) would be associated with a larger increase of $46 \%$ over baseline.

The bus journey times for each scenario at peak hour have been compared with each other using SPSS statistical software (Mann-Whitney non-parametric tests, which do not require a normal distribution) and the three scenarios were all significantly different from each other $(p<0 \cdot 001)$.

Running the model with 100 cyclists per hour (the 'very busy' case included in the TRL (2004) study), median peak hour bus journey times over London Bridge only increase by $2 \cdot 2 \%$ compared to the modelled baseline. This is indeed relatively negligible and hence it is unsurprising that the TRL observers detected no delays at those cycling volumes.

\section{Discussion}

\subsection{Limitations of this study}

This has been a small-scale study with many limitations. It is not possible to draw broader conclusions about specific delays one might expect at particular cycling volumes, which must be investigated on a case-by-case basis. The paper has, however, made the case for such investigation, where shared bus lanes are present or being considered, and current, expected and/or desired cycle flows are high. Shared bus lanes may delay buses in such contexts, perhaps more so than separated provision. 
Another limitation potentially relates to the possible impact of changes in speed limits. The speed limit (and hence desired speeds for buses) on London Bridge is currently $30 \mathrm{miles} / \mathrm{h}$; however, this may be reduced. Would a lower speed limit therefore cut bus delays, by bringing desired bus and cycle speeds closer? Currently, modelled average bus speed along London Bridge is $20 \cdot 0 \mathrm{miles} / \mathrm{h}$ at peak, excluding the reduction in speed caused by stopping at one of the two bus stops. (This was higher than the recorded speeds obtained for London Bridge from TfL by way of the iBus system; however, the latter included the acceleration or deceleration period when leaving or entering a bus stop.) Around half the cyclists have at present a desired speed below $20 \mathrm{miles} / \mathrm{h}$, retaining potential to delay buses. For the two COWI speed profiles, representative of the slower cyclist speeds one might expect with a more diverse cohort, the medians would be around $17 \mathrm{miles} / \mathrm{h}(27 \mathrm{~km} / \mathrm{h})$ and $14 \mathrm{miles} / \mathrm{h}(22.5 \mathrm{~km} / \mathrm{h})$, with nearly all having a desired speed below $20 \mathrm{miles} / \mathrm{h}$.

One final issue relates to black cabs, which in London are generally allowed to use bus lanes. These were not included in the model; nor were motorcycles, which can use TfL route network bus lanes. However, virtually no such vehicles used the bus lane during the morning peak, it being full of bicycles and buses, while the adjacent general motor traffic lane was almost empty. A different situation would have different implications for bus journey times. Moreover, reducing general motor traffic capacity to provide for cyclists could mean more taxis and motorcycles using the bus lane, unless restrictions were introduced.

\subsection{Summary of findings}

The modelling indicates that buses travelling northbound along London Bridge are impacted significantly by cyclists at current peak flows, with an $18 \%$ median increase in journey time at peak hour along this route segment, compared to there being no cyclists present. The route segment is very short and simple, containing for instance no intersections, so this result cannot be extrapolated across the network. However, the project highlights the importance of accurately modelling cyclists in existing and proposed schemes, where baseline and/or options involve shared road space between these and other vehicles, to more accurately gauge vehicular delay. It also suggests that separation of bus and cycle flows may have the potential to reduce bus delays.

\subsection{Implications for modelling}

Modelling cycles accurately can have substantial implications for understanding delays and effective highway capacity. Using standard capacity assumptions (TfL, 2013a, 2013b) the carrying capacity of the northbound bus lane might be approximately 750 vehicles. A bus lane carrying 58 buses and 2232 cycles $(0 \cdot 2$ PCU each) could then on paper still be safely under capacity. (A TfL road network route would additionally carry taxis and motorcycles, although this did not substantially affect bus operation in this case study.) However, the model shows substantial delays, illustrating the need to consider bus-cycle interactions at a granular level. This supports, and is supported by, the findings of Carrignon (2009) that a $0 \cdot 2$ PCU measure for cycles in mixed traffic is: $(a)$ too low, given lane width below $4 \mathrm{~m}$ and $(b)$ variable, with two-wheelers reaching saturation at $10 \%$ of flow.

The study highlights the importance of comprehensive site collected data. Here a significant amount of data was collected for traffic flows by vehicle type/lane and bus journey times. However, a more comprehensive previous study (COWI, 2013) was needed to help determine key cyclist specific parameters. These included speed profiles, acceleration/deceleration rates and behaviour-specific parameters (e.g. look-ahead distances, lateral behaviour) not available for London Bridge. Cyclists travelling across London Bridge are more aggressive and faster than those in Copenhagen, reinforcing the need for site-specific data. However, in low-cycling contexts modellers should consider how cyclist behaviour might change as cycling volumes increase. One likely reason for lower speeds of Copenhagen cyclists is the more equal gender split. Where an increase in cycling is being modelled, speed parameters from higher cycling contexts such as Copenhagen may be relevant.

Further work could examine how sharing space with motor vehicles affects cyclist journey times. Anecdotal evidence suggests that, in congested conditions, this can be substantial and encourage undesirable behaviour such as footway cycling. However, again this area is poorly understood. The study also suggests the utility of exploring ways of modelling cyclist behaviour separately from motor vehicles. Although the model was successfully parameterised, and provided useful information in an area with relatively little prior research, it highlighted the limitations of using driver behaviour as a model for cycling. Related problems have been observed for modelling shared space interactions between drivers and pedestrians (Gibb, 2015). This suggests the need to reconsider how to model the contexts in which road users interact, as well as the behaviour of the road users concerned.

\subsection{Implications for policy}

Tentative policy conclusions may be drawn. It seems likely that where cyclist volumes are very high (substantially more than the 100 per hour defined as 'high' in TRL (2004)) this causes delays to buses. Such delays are at present neither well understood nor included in modelling work. Yet in London and in some other towns and cities in the UK, these volumes are being seen at peak hours on key bus routes, while current trends and targets suggest even higher cycling volumes will be experienced in the future.

Hence, in principle, reducing the numbers of cyclists in bus lanes through alternative provision might help reduce bus delays. There will be a trade-off involved if, for example, buses are then delayed at junctions due to the need to accommodate cyclists separately. However, this would need to be considered 
empirically from case to case. Planners should be aware that where high cyclist volumes are experienced or predicted, shared bus lanes may cause bus delays that remain unrepresented in standard modelling approaches. While the bus lane modelled here is $3 \mathrm{~m}$, even $4.5 \mathrm{~m}$ lanes (as found in some London streets) might create some delays, because drivers would be unwilling to overtake cyclists close to stops. Moreover, given a bicycle 'envelope' of $0.75 \mathrm{~m}$, and a recommended passing distance of 1.5 (as currently used in campaigns by a number of English police services, such as 'Give space, be safe'), a $2.5 \mathrm{~m}$ wide bus still cannot necessarily safely overtake a cyclist where there is a vehicle in an adjacent lane.

There are additional reasons for not mixing buses and cycles, particularly where high cycling flows exist or are desired. First, mixing with buses can be frightening for cyclists, with dangerous overtaking or bicycle-following behaviours potentially common (De Ceunynck et al., 2015). Second, cyclists and potential cyclists see even wide bus lanes, even those with $20 \mathrm{miles} / \mathrm{h}$ speed limits, as substantially inferior to separate provision (Aldred, 2015). Where there is space for $4.5 \mathrm{~m}$ bus lanes, it may be possible to provide at least light segregation alongside narrower bus lanes. Sharing is particularly problematic where children are involved (Aldred, 2015). However, this paper is distinctive in highlighting that such separation can potentially positively impact bus passengers and bus operations.

Removing or reducing high volumes of cyclists from bus lanes could be done in different ways. It is impractical to ban cyclists from bus lanes in conditions of high cycling flows, and would lead to substantial delays for, and conflicts with, general motor traffic. Two options are described below.

(a) The creation of separated cycle tracks, thus removing cyclists from bus lanes (although in the UK, cyclists would still be permitted to use the bus lanes, few will do so with tracks present). This would in principle substantially reduce bus delays where cyclist volumes are high. It will require taking space from other users: whether general traffic, buses, or pedestrians, or a combination. Sustainable transport goals would suggest this space should be taken from general traffic. However, in practice there might be some disbenefit for buses, which would have to be balanced against the reduction in delays caused by the separation of modes.

Separated tracks are increasingly being implemented on main roads in UK cities. They will, to be consistent, involve routing cyclists behind bus stops, so bus passengers need to cross the cycle track to board or alight from a bus. This entails decisions about whether pedestrians or cyclists should be given priority at such points. In the UK, where bus stop 'bypasses' and 'boarders' are still relatively rare, different arrangements are being tested. If bus and passenger flows are low, cyclist priority may be appropriate, but in contexts with higher pedestrian flows, pedestrian priority may be needed. Although cycle-pedestrian conflicts are low risk compared to cycle-bus or bus-pedestrian conflicts, designs must be mindful of the comfort of more vulnerable passengers.

(b) The creation of parallel routes that prioritise cyclists, so that they are less likely to use bus lanes. There are examples of this approach in London; for example, the Tavistock-Torrington Place cycle tracks in Camden are an alternative to the very busy Euston Road (a bus route). Parallel routes must be of high quality and nearby to attract cyclists; they must link useful destinations without excessive detour and provide adequate capacity to cater for predicted/desired flows, or cyclists will continue to use bus lanes.

Where cyclists currently routinely share space with buses, policy-makers should consider developing a matrix to guide decisions about mixing or separation. It is recommended here that such a matrix should use desired rather than current cycling and bus flows, because shared bus lanes are a relatively unattractive provision for cycling, particularly by underrepresented groups such as women, older people and children. The planning process should aim to provide networks of both cycle and bus routes that are sufficiently high in quality and dense to attract mass custom, given the high efficiency of both modes. Decisions may then be taken to re-route cycle or bus networks to provide better for both modes (Figure 11).

\section{Conclusions}

Planners may be wrong if they assume cyclists do not delay buses in shared lanes. At high cycling volumes, delays may be

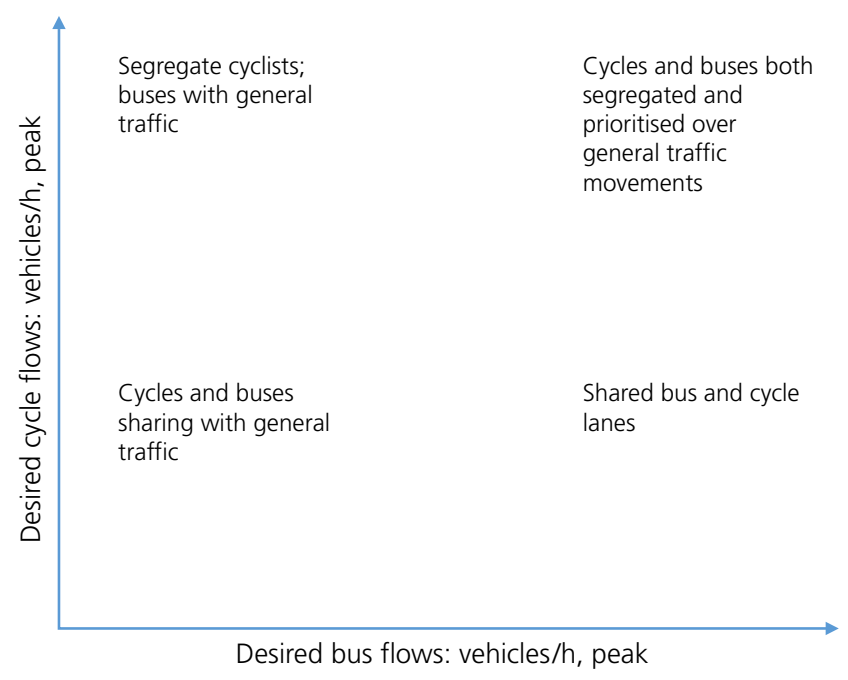

Figure 11. Example matrix of provision 
substantial and may increase in a non-linear fashion, particularly if cycling becomes more demographically diverse. Hence, creating separated space for cyclists does not necessarily detract from bus provision. It may even improve it, if space is taken from private cars. In this case, there may be a double benefit: buses would benefit directly from no longer being delayed by cycles, and would become relatively more attractive compared to the car.

The extent or existence of any benefit for buses must be determined on a case-by-case basis: this paper has only shown the principle is valid. Efforts to improve the modelling of cyclists are also recommended: current microsimulation packages are limited in their ability to represent actual cycling behaviour. For this relatively simple project, manipulation of parameters was sufficient to represent cyclist behaviour. However, substantial improvements need to be made to modelling to enable a more realistic depiction of cycling, and hence better predict outcomes of interest.

\section{Acknowledgements}

The authors would like to thank CILT and TfL for their financial support for this study. Thanks also go to Alan Bain, who contributed to the project, and others including Stuart Gibb (CH2M), Claudia Penaranda, Brian Deegan, Simon Lusby and David Field (TfL), who provided comments on the paper and project. None of the organisations or individuals acknowledged here is responsible for the views expressed in this paper.

\section{Appendix: Vissim parameters used}

The following provides more detail on the parameters altered from either the London default settings or those used in the COWI study.

Other than at bus stops, all buses use a behaviour named 'Vehicles overtaking', with the following parameters the highlighted parameters are those which have been changed from standard urban driver behaviour (see Figures 12-14).

Other than at bus stops, all cyclists use a behaviour named 'Multimodal settings', with the following parameters the highlighted parameters are those which have been changed from standard urban driver/cyclist behaviour (see Figures 15-17).

At bus stops, cyclists use a behaviour named 'Multimodal settings - bus stop' if there is a bus present - the highlighted parameters are those which have been changed from 'Multimodal settings' (see Figures 18 and 19).

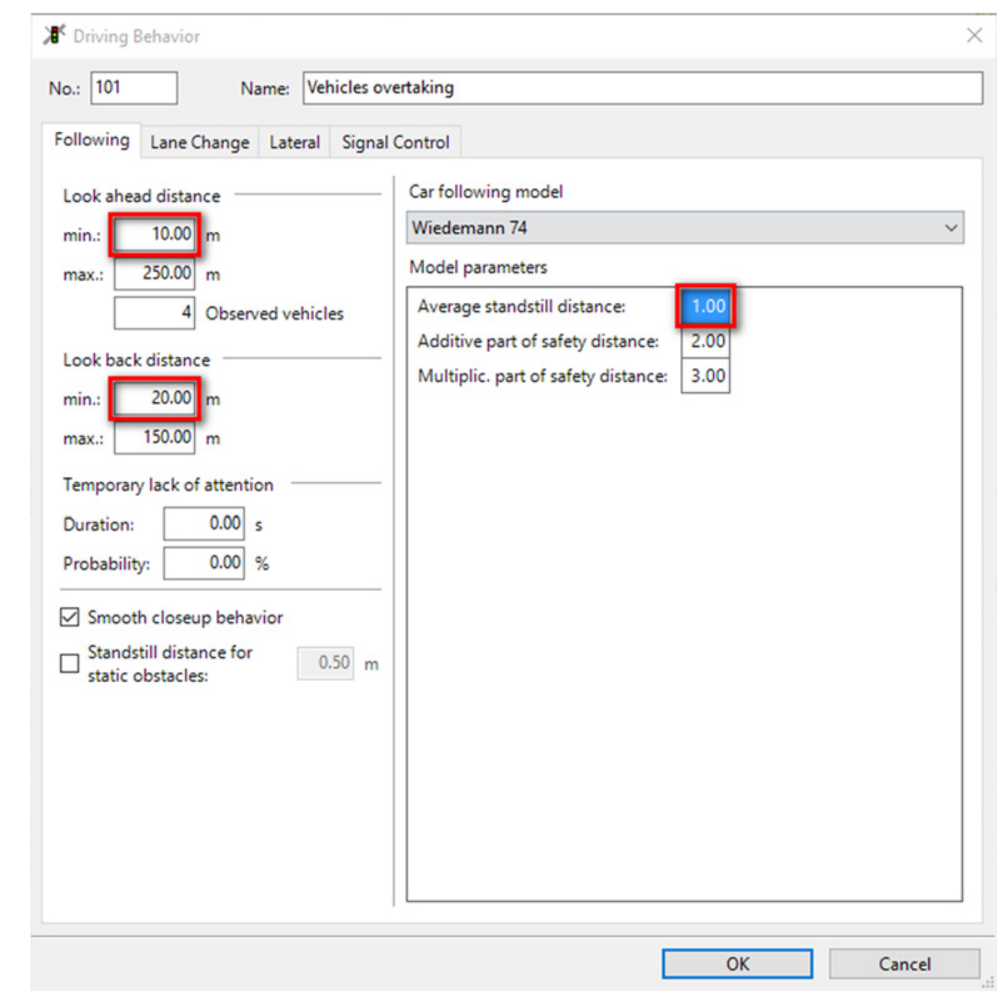

Figure 12. Vissim driver behaviour: vehicles overtaking - following 
Transport

Volume 172 Issue TR3
Cyclists in shared bus lanes: could there be unrecognised impacts on bus journey

times?

Aldred, Best and Jones

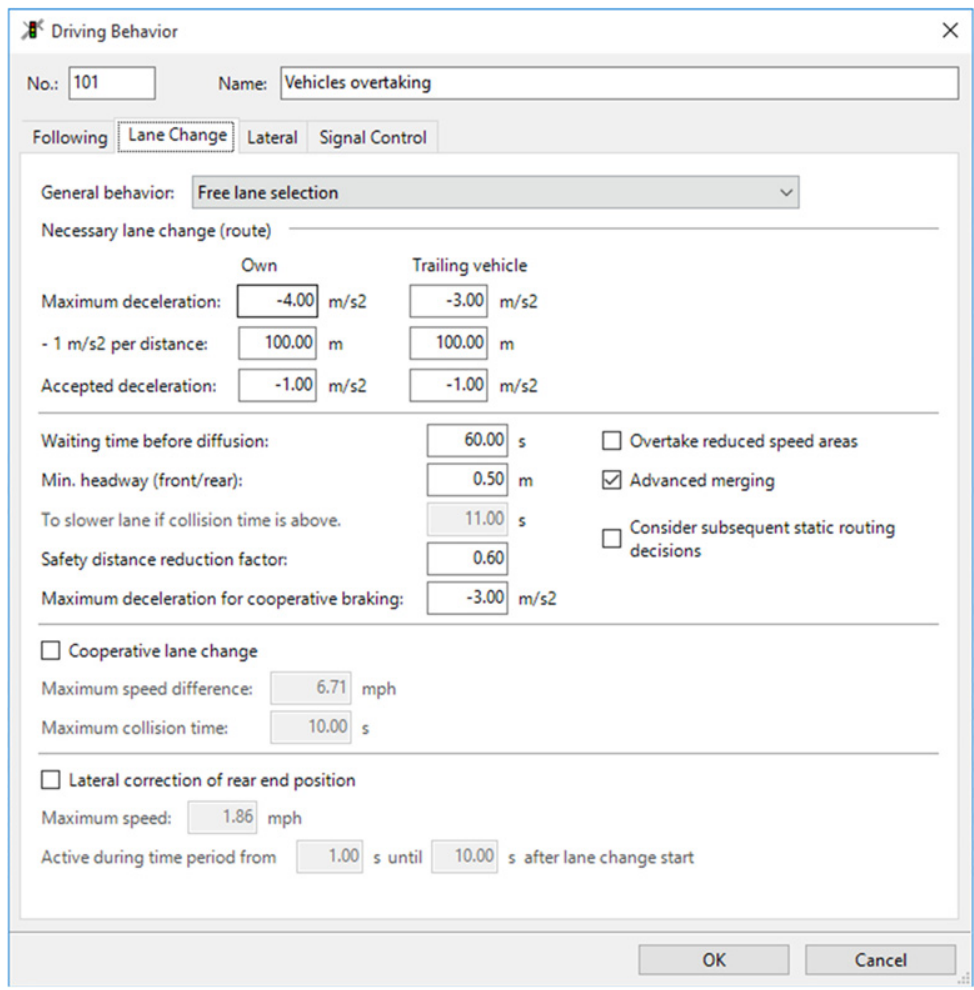

Figure 13. Vissim driver behaviour: vehicles overtaking - lane change

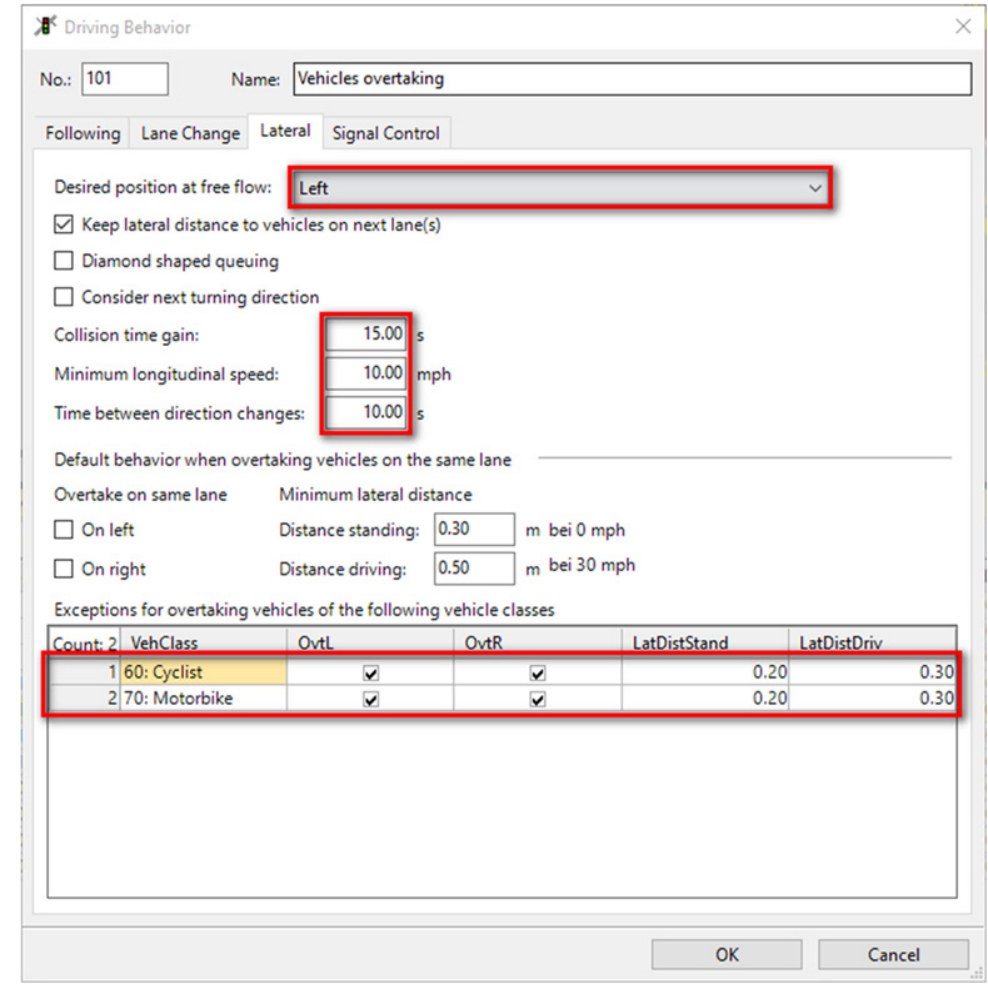

Figure 14. Vissim driver behaviour: vehicles overtaking - lateral 


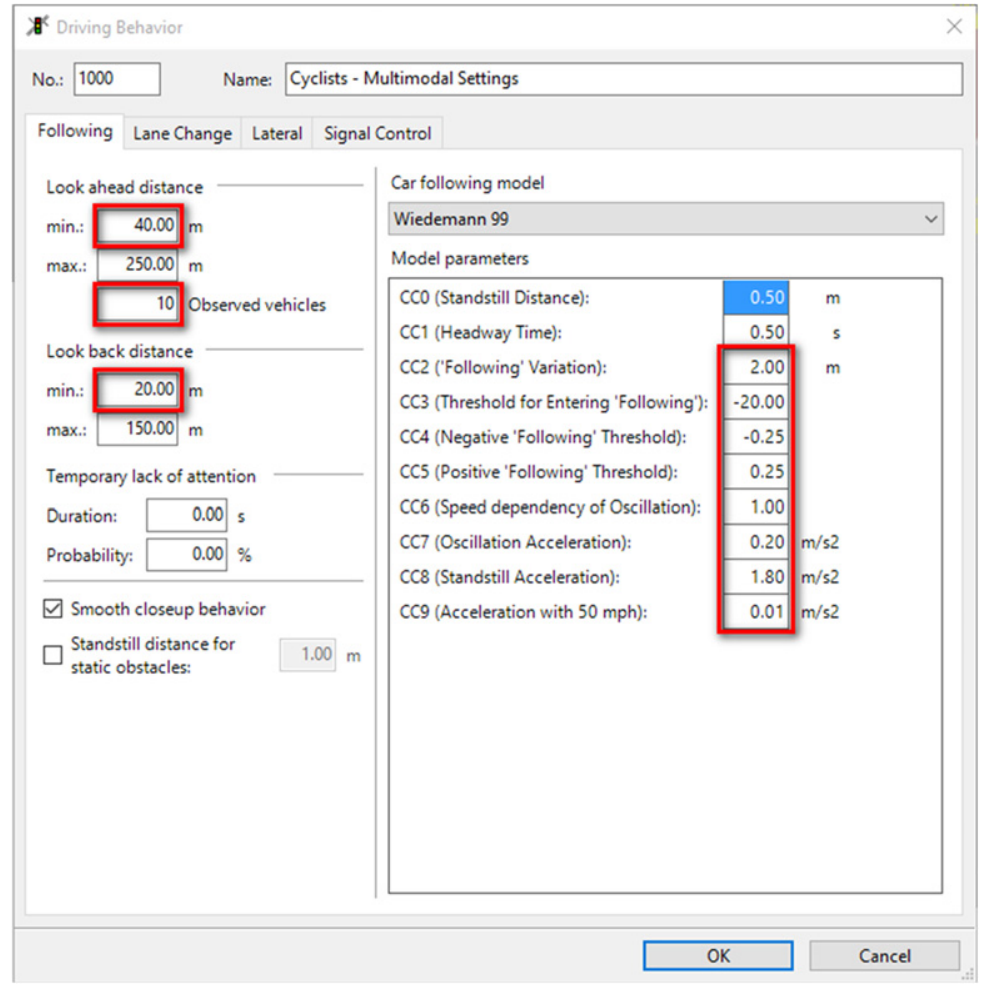

Figure 15. Vissim driver behaviour: multimodal settings - following

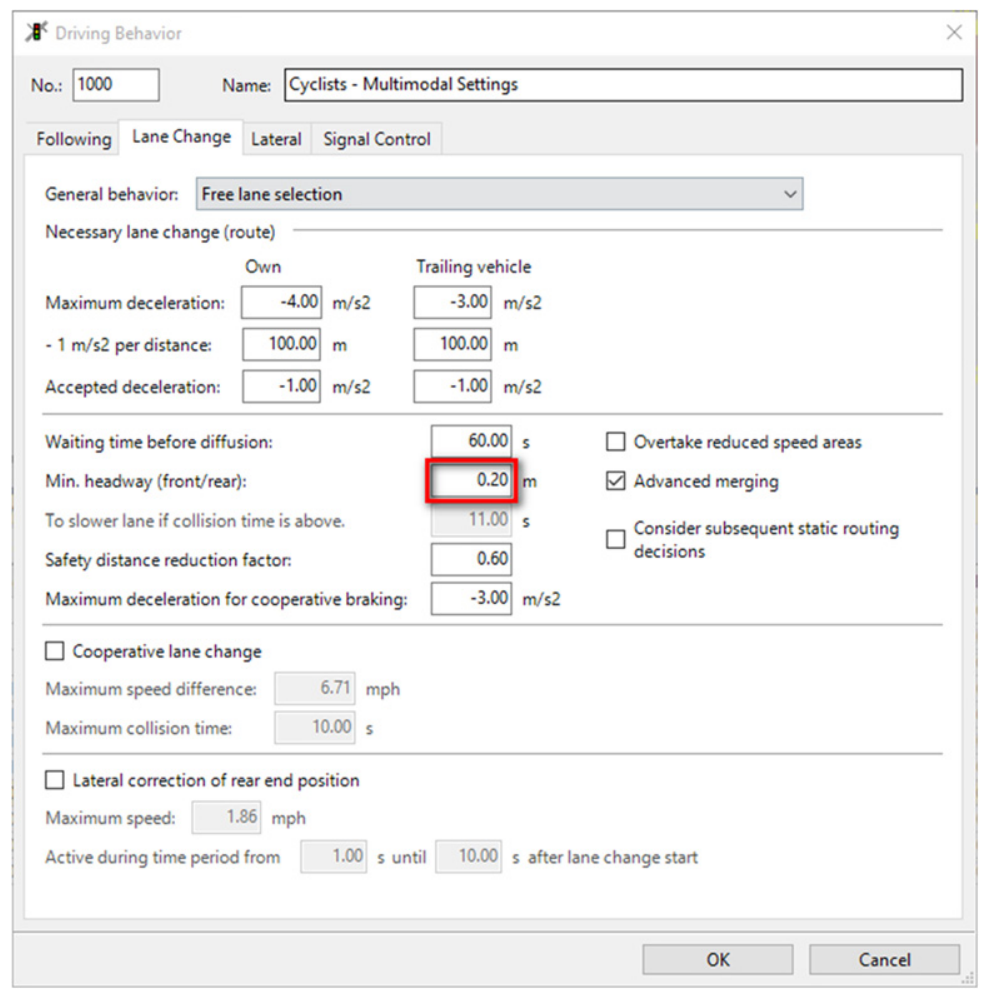

Figure 16. Vissim driver behaviour: multimodal settings - lane change 


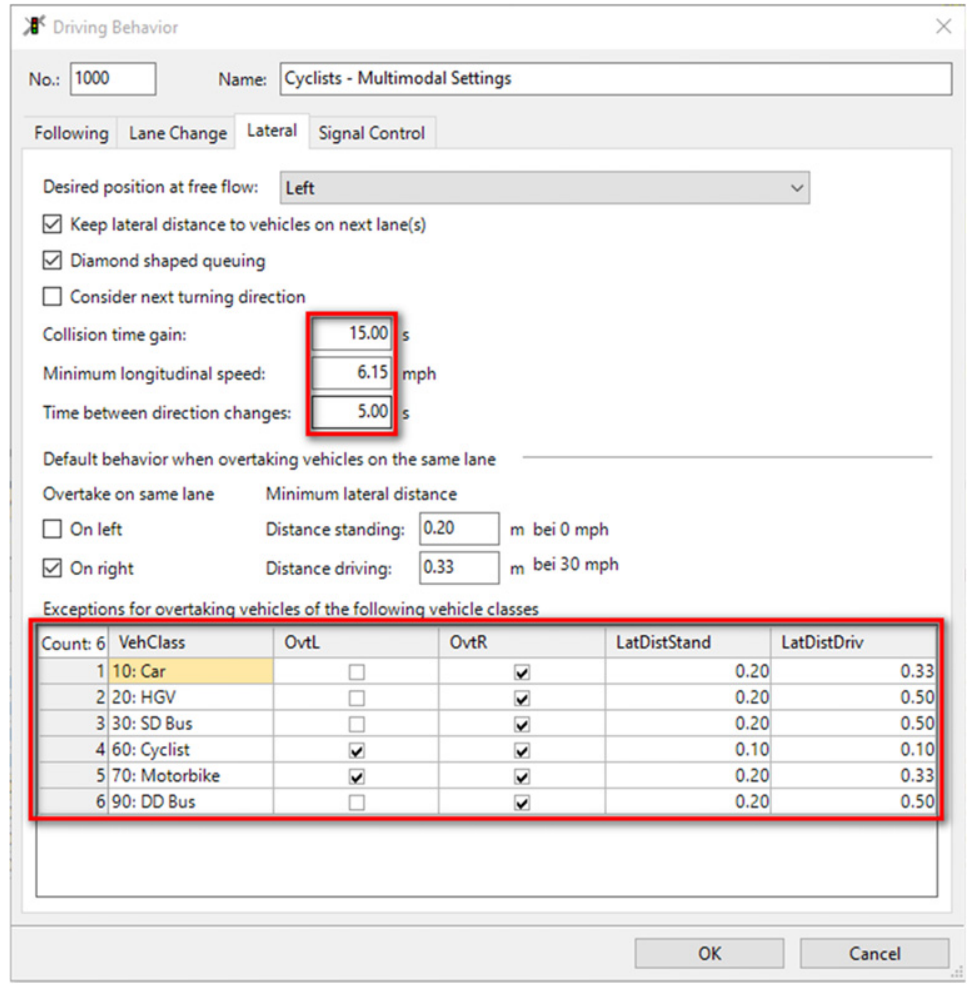

Figure 17. Vissim driver behaviour: multimodal settings - lateral

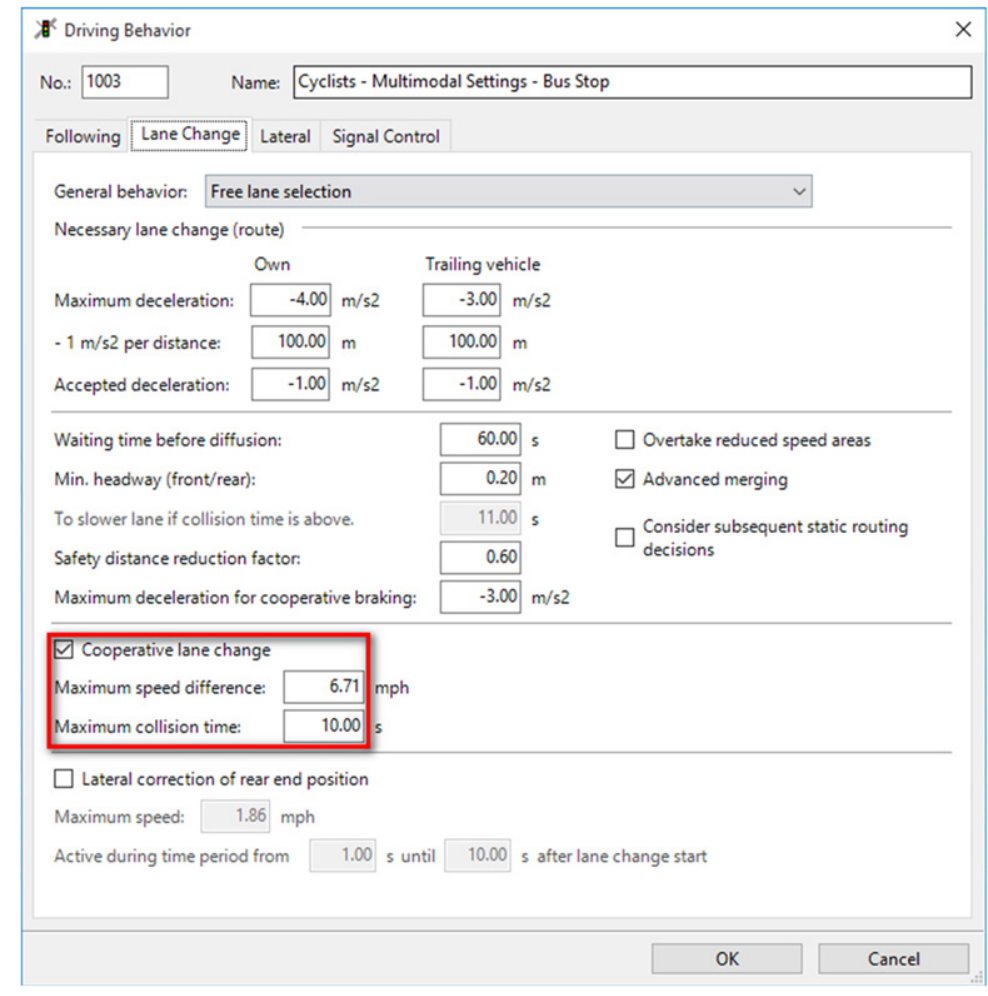

Figure 18. Vissim driver behaviour: multimodal settings - bus stop - lane change 


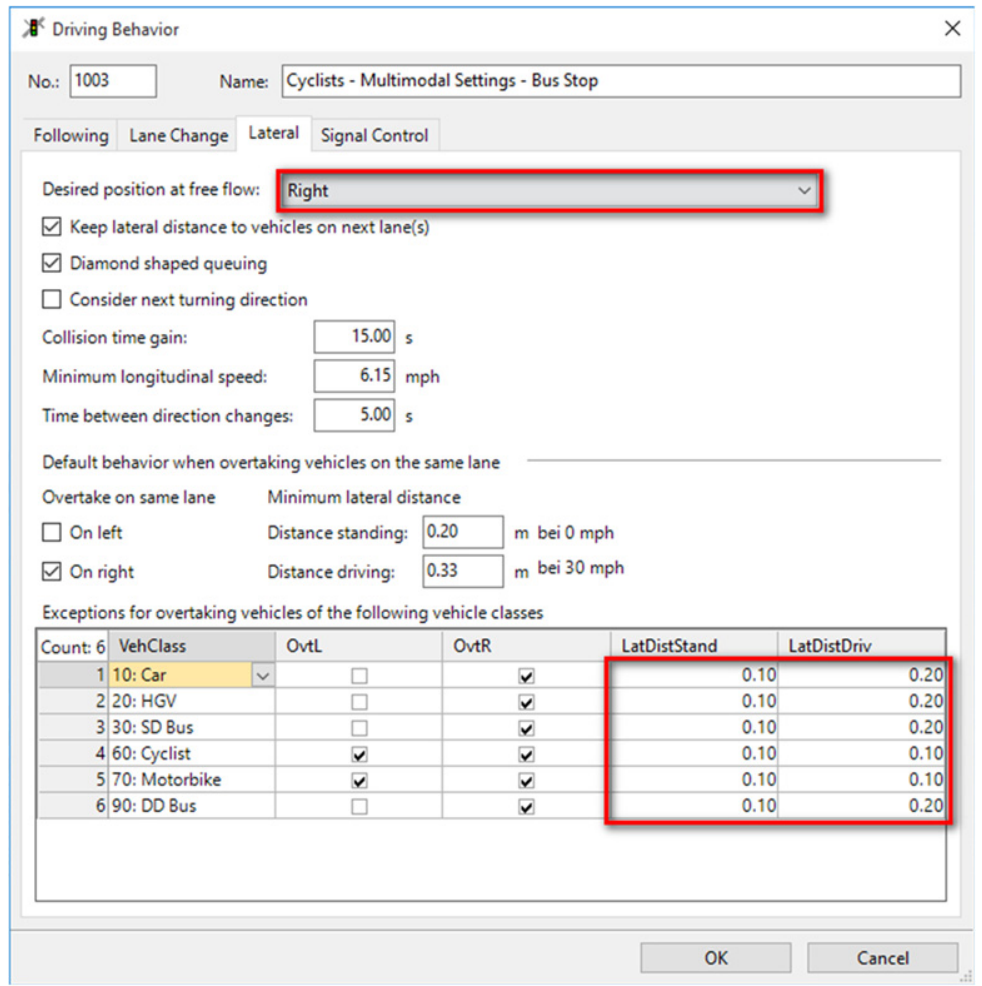

Figure 19. Vissim driver behaviour: multimodal settings - bus stop - lateral

\section{REFERENCES}

Aldred R (2015) Adults' attitudes towards child cycling: a study of the impact of infrastructure. European Journal of Transport and Infrastructure Research 15(2): 92-115.

Aldred R and Crosweller S (2015) Investigating the rates and impacts of near misses and related incidents among UK cyclists. Journal of Transport \& Health 2(3): 379-393.

Banister D (2008) Unsustainable Transport: City Transport in the New Century. Routledge, London, UK.

Carrignon D (2009) Assessment of the impact of cyclists on heterogeneous traffic. Traffic Engineering and Control 50(7): 323-325.

CoWI (2013) Micro Simulation of Cyclists in Peak Hour Traffic. COWI, Copenhagen, Denmark.

Cycling England (2010) A10 Bus Lanes and Bus Stops. Cycling England, London, UK. See https://www.cycling-embassy.org.uk/ sites/cycling-embassy.org.uk/files/documents/cyclingengland/2011/ 01/a10_bus_lanes_and_bus_stops.pdf (accessed 24/08/2017).

Davies D, Chinn L, Buckle G and Reid S (2003) Cycling in Vehicle Restricted Areas. Transport Research Laboratory, Crowthorne, UK.

De Ceunynck T, Dorleman B, Daniels S et al. (2015) Sharing is (s)caring? Interactions between buses and bicyclists on bus lanes shared with bicyclists. Proceedings of the 28th ICTCT Workshop, Ashod, Israel. See http://www.ictct.org/wp-content/uploads/ 151214De-Ceunynck-et-al-sharing-is-scaring_ICTCT.pdf (accessed 01/09/2017).

DfT (Department for Transport) (1996) Design Manual for Roads and Bridges: Volume 12, Traffic Appraisal of Roads Schemes, Section 2 Traffic Appraisal Advice, Part 1: Traffic Appraisal in Urban Areas. DfT, London, UK. See http://www.standardsforhighways.co.uk/ha/ standards/dmrb/vol12/section2/12s2p1.pdf (accessed 04/04/2017).

Dft (2004) Bus Priority: the Way Ahead. Resource Pack Edition 2. DfT, London, UK. See http://www.dft.gov.uk/pgr/regional/buses/ bpf/busprioritythewayahead12/rioritythewayaheadpdfversion.pdf (accessed 24/08/2017).

DfT (2016) National Travel Survey Table NTS0906. Car Occupancy by Trip Purpose. DfT, London, UK. See http://www.gov. uk/government/statistical-data-sets/nts09-vehicle-mileage-andoccupancy (accessed 04/11/2016).

El-Geneidy A, Krizek KJ and lacono M (2007) Predicting bicycle travel speeds along different facilities using GPS data: a proof of concept model. In Proceedings of Transportation Research Board Annual Meeting. Transportation Research Board, Washington, DC, USA, paper no. 07-2971 (CD-ROM).

Gibb S (2015) Simulating the Streets of Tomorrow: An Innovative Approach to Modelling Shared Space. Association for European Transport, Henley-in-Arden, UK. See http://vision-traffic. ptvgroup.com/fileadmin/files_ptvvision/Downloads_N/0_General/ 1_Use_Cases/Simulating_The_Streets_Of_Tomorrow_ CH2MHILL.pdf (accessed 14/03/2016).

GLA (Greater London Authority) (2013) The Mayor's Vision for Cycling in London: An Olympic Legacy for All Londoners. TfL, London, UK. See http://www.london.gov.uk/sites/default/files/cycling vision_gla_template_final.pdf (accessed 10/07/2017).

Kara D, Koesling S, Kretz T et al. (2014) Microsimulation - a robust technical planning method with strong visual output. Proceedings of the Institution of Civil Engineers - Civil Engineering 167(5): 17-24, http://dx.doi.org/10.1680/cien.13.00015.

Kohli S, Inayathusien A and Caulfield R (2014) Modelling impacts of cycling in highway network models. Proceedings of European Transport Conference, Frankfurt, Germany. Association for European Transport, Henley-in-Arden, UK.

Kretz T, Reutenauer F and Schubert F (2013) Multimodal simulation-based planning for pedestrians. In Proceedings of Transportation Research Board Annual Meeting. 
Cyclists in shared bus lanes: could there be unrecognised impacts on bus journey

times?

Aldred, Best and Jones
Transportation Research Board, Washington, DC, USA, paper no. 13-1943.

London TravelWatch (2014) Response to TfL's Cycle Superhighway Consultations. London TravelWatch, London, UK. See http://www. londontravelwatch.org.uk/documents/get_lob?id=3897\&age=\& field=file (accessed 14/03/2016).

Naess P, Andersen J, Nicolaisen MS and Strand A (2014) Transport modelling in the context of the 'predict and provide' paradigm. European Journal of Transport and Infrastructure Research 14(2): 102-121.

Pein W (1997) Bicyclist performance on a multiuse trail. Transportation Research Record 1578: 127-131.

Singh A (2012) A study of cyclist behaviour on shared space. Proceedings of 1 st Civil and Environmental Engineering Student Conference, London, UK.

Strava (2017a) http://analytics.strava.com/segments/766649 (accessed 10/07/2017).

Strava (2017b) http://analytics.strava.com/segments/766121 (accessed 10/07/2017).

TfL (Transport for London) (2009) Attitudes to Bus Priority Schemes. TfL, London, UK, Research Report. See http://www.tfl.gov.uk/ $\mathrm{cdn} / \mathrm{static/cms/documents/attitudes-to-bus-priority-schemes-report.}$ pdf (accessed 14/03/2016).

TfL (2010) Cycling Behaviour Survey. TfL, London, UK

TfL (2012) Cycle Route Choice Study. TfL, London, UK. See http://content.tfl.gov.uk/understanding-cycle-route-choice.pdf (accessed 10/07/2017).
TfL (2013a) Cycle Census: Technical Note. TfL, London, UK, Research Report. See http://content.tfl.gov.uk/cycle-censustechnical-note.pdf (accessed 14/03/2016).

TfL (2013b) Roads Task Force - Technical Note 10 What is the Capacity of the Road Network for Private Motorised Traffic and How has this Changed Over Time? TfL, London, UK. See http://content.tfl.gov. uk/technical-note-10-what-is-the-capacity-of-the-road-network-forprivate-motorised-traffic.pdf (accessed 14/03/2016).

TfL (2015a) Travel in London 8. TfL, London, UK. See http://content. tfl.gov.uk/travel-in-london-report-8.pdf (accessed 14/03/2016).

TfL (2015b) London Cycling Design Standards. TfL, London, UK

TRL (Transport Research Laboratory) (2004) Cyclists in Bus Lanes. TRL, Wokingham, UK. See http://www.trl.co.uk/online_ store/reports_publications/trl_reports/cat_traffic_engineering/ report_cycling_in_bus_lanes.htm (accessed 10/07/2017).

Twaddle H, Schendzielorz T and Fakler O (2014) Bicycles in urban areas: review of existing methods for modelling behavior. In Proceedings of the 93rd Annual Meeting of the Transportation Research Board. Transportation Research Board, Washington, DC, USA, pp. $140-146$.

Wedderburn M (2015) Planning for people and pedals: integration of walking and cycling in transport modelling and analysis. Proceedings of European Transport Conference 2015, Frankfurt, Germany. Association for European Transport, Henley-in-Arden, UK.

Wood S (2012) Traffic microsimulation - dispelling the myths. Traffic Engineering and Control 53(9): 339-344. 